\title{
El amor interracial en dos obras narrativas del siglo XIX: Mercedes, de Soledad Acosta, y Florencio Conde, de José María Samper*
}

\section{Juan Carlos Herrera Ruiz ${ }^{* *}$}

Recibido: 10 de agosto de 2016

Enviado a pares evaluadores: 10 de septiembre de 2016

Aprobado por pares evaluadores: 14 de octubre de 2016 Aprobado por Comité Editorial: 21 de octubre de 2016 DOI: 10.22395/csye.v5n10a3

\section{RESUMEN}

Este artículo contrasta dos obras narrativas colombianas del siglo XIX: Mercedes (1869), de Soledad Acosta de Samper, y Florencio Conde (1875), de José María Samper Agudelo, en las que el tema del amor entre el hombre negro y la mujer blanca funge como representación del proceso fundacional de la nación y de las resistencias que este enfrenta en los prejuicios y en la estratificación sociorracial remanentes de la época colonial. La sinopsis de cada relato fluye acompañada de un intento de interpretación que se enfoca en el modo en que la voz narrativa traza una imagen del negro y le atribuye una noción del amor. Se propone, además, una relación instrumental entre este tipo de literatura y el proceso de consolidación de nuevas naciones y de nuevas identidades nacionales.

Palabras clave: Soledad Acosta de Samper; José María Samper; literatura colombiana siglo XIX; amor interracial.

Artículo producto de la participación en el Seminario de Literatura colombiana en el marco del Doctorado en Literatura, de la Universidad de Antioquia.

** Antropólogo y candidato a doctor en Literatura de la Universidad de Antioquia. Docente de tiempo completo de la Facultad de Ciencias Económicas y Administrativas de la Universidad de Medellín. Correo electrónico: jcherrera@udem.edu.co 


\section{Interracial love in two narrative works of the nineteenth century: Mercedes, of Soledad Acosta, and Flopencio Conde, of José María Samper}

\section{ABSTRACT}

This article compares two Colombian narrative works of the nineteenth century: Mercedes (1869) by Soledad Acosta de Samper and Florencio Conde (1875) by José María Samper Agudelo, in which the theme of love between a black man and a white woman serves to exemplify a process of national foundation that faces resistance in the remaining colonial socio-racial stratification and prejudices. Synopsis of each story flows together with an attempt at interpretation that focuses on the way the narrative voice draws a picture of the afrodescendant and the sense of love he is credited with. An instrumental relationship between this type of literature and the consolidation of new nations and new national identities is also proposed.

Keywords: Soledad Acosta de Samper; José María Samper; Colombian literature of the nineteenth century; interracial love. 


\section{Introducción}

En la introducción a su ensayo Piel negra, máscaras blancas (2009), Frantz Fanon emite una fórmula bastante propicia como preámbulo a un ejercicio de reflexión en torno a dos obras narrativas colombianas del siglo XIX: "Para el negro no hay más que un destino. Y es blanco". Ello como invitación a admitir que la ontología del negro ha sido y es un constructo atribuible al blanco y que finalmente es la visión del conquistador la que prevalece.

En la experiencia americana de esta construcción la literatura cumple desde la conquista una función instrumental: la de contribuir a forjar una imagen del ser negro -o negra-, de su condición histórica y social, de su vida cotidiana y cultura material, o bien de lo admirable o reprochable de su carácter. Dentro del universo de manifestaciones que configuran un perfil, una en particular ocupa el centro de atención para el análisis que sigue: la del negro frente al amor13 y la noción del amor que le viene atribuida desde la ficción, a través de una estrategia que enfatiza en el color de la piel; ello como rasgo ineluctable, al que la retórica del blanco ha subordinado las demás manifestaciones y sentimientos humanos.

Los relatos Mercedes (1869), de Soledad Acosta de Samper (1833-1913), y Florencio Conde (1875), de José María Samper Agudelo (1828-1888) son expresiones de cómo dos intelectuales, a la sazón esposos, ensayaron modelar desde la ficción literaria una imagen del negro como sujeto afectivo y como sujeto histórico, en un contexto imaginado a lo largo de la primera mitad del siglo, en el que los ideales democráticos y de igualdad de la recién alcanzada independencia entraban en pugna con los prejuicios de una sociedad aun influenciada por el esclavismo y el régimen haciendal, arquetipos de arraigo colonial que alimentaron por siglos la idea de que el negro era inferior al blanco y de que por ello estaba destinado a otro género de vida.

El recurso que viene utilizado para vehicular la construcción de esta imagen en sendos relatos es el del romance entre el hombre negro -o mestizo- y la mujer blanca, romance que supone la integración de los géneros raciales a la inversa de como solía ser en la recién superada época colonial, esto es, entre el hombre blanco y la mujer negra -en cualquier caso diferente de los demás enlaces socialmente aceptados entre blancos, indígenas y negros-, todo ello en medio y como parte de las tensiones generacionales derivadas tanto del proceso independentista (aspecto más marcado para el caso de Mercedes) como del proceso fundacional de la nación y del reformismo criollo en las cuatro décadas ulteriores (al cual alude la mayor parte del relato en Florencio Conde).

Por el vocablo "Amor" entiéndase su acepción más general del Diccionario de la Real Academia: "Sentimiento intenso del ser humano que, partiendo de su insuficiencia, necesita y busca el encuentro y unión con otro ser". 
Esta suerte de romance interracial, la del "amante negro" planteado como tema literario, fue recurrente en el romanticismo europeo (Sommer, 2004, p. 168); aunque menos frecuente, no fue del todo ajeno al siglo XIX hispanoamericano24, y hablar de ello en las referidas obras implica, a su vez, hablar de mestizaje, interculturalidad y, desde luego también, de perspectiva de género; pero el aspecto o la dimensión que se busca resaltar aquí -pues en últimas encierra todas las demás- se relaciona con la función social e histórica de la literatura en ese siglo, función estrechamente asociada a lo que Ángel Rama (1985, p. 67) identifica como una dinámica de consolidación de nuevas naciones y de nuevas identidades nacionales, que se da en conjunción con la creación de una nueva literatura servil a ese propósito fundacional. En esta misma dirección, Ordóñez (1997, p. 25) percibe en las obras de la primera etapa, como novelistas, de Acosta y de Samper -la cual ubica entre 1866 y 1876- una intención por crear una literatura nacional, que contribuyera a edificar una conciencia de nacionalidad, a instruir a los lectores en los valores democráticos y progresistas del pensamiento moderno, a través del desarrollo de un género discursivo subsidiario del proyecto educativo y cultural de la nación. Visto desde esta perspectiva son varios los rasgos en común observables en las obras en cuestión -así como los contrastes- y sobre ello se desplazará la atención más adelante; de momento baste manifestar que el propósito de esta composición consiste en sacar a la luz parte del lenguaje a través del cual fluyen la atracción y el diálogo amoroso entre seres de razas aisladas por la historia, así como discurrir por el modo en que dichos seres elaboran una inter-subjetividad como pareja y en relación con los arquetipos genéricos que de cada sexo se describen. Dejando de lado el problema que opone entender dicha inter-subjetividad diferencialmente desde la visión del hombre o de la mujer -no porque ello carezca de importancia sino porque implicaría plantear la cuestión de otro modo-se estima de mayor provecho para

\footnotetext{
La novela Sab (1841), de Gertrudis Gómez de Avellaneda, es un ejemplo análogo donde se representa el amor de un esclavo hacia una dama de la aristocracia en la Cuba de principios de siglo; Paulina Barrenechea (2009) documenta la existencia de una leyenda en verso, El Bandido (1846), del escritor chileno Fernando Santiván, donde se narra la historia de un esclavo que rapta la nieta de su amo en venganza por las vejaciones sufridas por cuenta de su condición racial; por último, valga citar el breve relato La Emplazada (1874), del peruano Ricardo Palma, en la que se narra la historia del mulato Pantaleón, una especie de esclavo preferido y cultivado que llama la atención de su propietaria, una condesa viuda que lo convierte en su amante y a quien ulteriormente ordena matar como castigo al descubrir que la traicionaba con otra de sus esclavas. Un ejemplo representativo de este tipo de historias en lengua inglesa es Belinda (1810), novela de la escritora irlandesa María Edgeworth, ambientada en la Jamaica colonial, en la que viene representada la atracción y el cortejo de dos de sus personajes, un esclavo negro y un mestizo caribeño (creole) rico, hacia dos señoritas blancas de origen inglés; asimismo, en el relato autobiográfico Vida de un esclavo americano contada por él mismo (1845), del estadounidense Frederick Douglas, se narra la vida de un afroamericano que en medio de las vicisitudes dedica su vida a la lucha por el abolicionismo universal de la esclavitud, y que ya en su madurez contrae segundas nupcias con una mujer blanca. En contraste con los ejemplos anteriores, pero siempre en el terreno del amor interracial, la canónica novela cubana Cecilia Valdés o la loma del Ángel (1839) de Cirilo Villaverde, representa un ejemplo paradigmático, valga decir, entre muchos otros durante el siglo XIX en Colombia y en Latinoamérica, en los que el romance involucra al hombre blanco con la mujer negra o mulata.
} 
esta propuesta de re-lectura apuntar a identificar en la voz narrativa de cada relato -la que no sobra resaltar que es blanca- los recursos narrativos a través de los cuales se concreta la experiencia del amor entre el negro y la blanca, y se confiere a esta unión un lugar y un rol, desde luego no exentos de prejuicios, en el ámbito de la nuevas relaciones sociales que devienen con la independencia y la ulterior fundación de la nación neogranadina.

Parte del marco conceptual con que se propone aproximar la faceta del amor en Mercedes y en Florencio Conde es la tesis que entrega Doris Sommer en su libro Ficciones fundacionales: las novelas nacionales de América Latina, en el cual se traza una nítida conexión entre la novela del siglo XIX y las bases ideológicas a partir de las cuales se estructuran los Estados nacionales, conexión que se produce justamente a través del uso sistemático del sentimiento del amor heterosexual, como insumo para la creación de escenarios históricos donde se entretejen semánticamente la noción de lo político y la de lo erótico; para ello aborda el estudio de varias novelas -entre ellas María, de Jorge Isaacs- que sirven de ejemplo ilustrativo en Hispanoamérica de eso que postula como "una intimidad nacional", en las que se explota sistemáticamente el tema de los amores imposibles o trágicos y se recurre a una "evocación casi masoquista de placeres inalcanzables, y se emplea una narrativa reflexiva que se vuelve sobre el lector como un látigo para acrecentar el deleite sentimental" (Sommer, 2004, p. 230). Mercedes y Florencio Conde encajan en cierta medida en este tipo de proposición del amor percibido como imposible, al ser las relaciones representadas allí de algún modo transgresivas del viejo paradigma racial que se resiste al cambio del ciclo histórico.

En este este sentido, son frecuentes en sendos relatos las toponimias y las referencias a personajes y acontecimientos reconocibles por el lector en su horizonte cognitivo de la historia de ese siglo. Esta marca de la historia que se hace evidente en estas y otras obras narrativas de Soledad Acosta y de Samper ha sido documentada desde la historiografía novelística colombiana de ese periodo: para el caso de Samper, algunos investigadores de la segunda mitad del siglo XX enfocan su trabajo crítico y de interpretación en un presunto paralelo existente entre sus novelas y las luchas políticas a las que adhirió este escritor a lo largo de su vida; asimismo inquieren por las corrientes ideológicas y estéticas que pudieron haber influenciado su producción a lo largo de su carrera como escritor y como figura pública (Cristina, 1976; Williams, 1991; Rodríguez-Arenas, 2004; D'Allemand, 2102), postulando con ello en modo directo o indirecto, la presencia de un alter ego de Samper en el perfil político y moral de los personajes que crea dentro de sus obras de ficción.

En lo que respecta a Soledad Acosta, cabe destacar el creciente interés registrado en las últimas tres décadas por sacar a la luz una gran parte de su 
muy extensa obra aún desconocida, que al igual que en Samper comprende, además del cuento y la novela, variedad de géneros: poesía, ensayo, periodismo, crónicas de viajes, traducciones, obras didácticas (Alzate \& Ordoñez 2005). En opinión de Ordóñez, la narrativa de Soledad Acosta "hay que valorarla como la de alguien que está participando en la creación y definición de los nuevos géneros discursivos de su momento histórico y literario" (1997, p. 385), y ello va en consonancia con las ya citadas tesis de Ángel Rama y de Sommer respecto al carácter instrumental de la literatura en la fundación de naciones. Pero, más allá de ponderar la dimensión social y cultural y de la concepción de identidad en su polifacética obra narrativa, los estudios sobre Soledad Acosta apuntan también a desentrañar la simbología de un lenguaje que postula la existencia de un "yo" de mujer, de una subjetividad que se manifiesta en sentimientos que se definen ya no solo desde la individualidad, sino también desde la perspectiva de un género: masculino o femenino. Aparte de los ya citados y dentro del conjunto de trabajos que siguen esta línea de aproximación a la obra de Soledad Acosta cabe citar, entre otros, el de Flor María Rodríguez-Arenas, quien documenta la trayectoria de esta escritora y advierte lo revolucionario -teniendo en cuenta la época en que escribió- de una labor literaria que "aboga por una mejor educación de la mujer y lucha por romper algunos lastres culturales que anclan a la mujer en la tradición de que la condena a permanecer en el ámbito de lo doméstico, de la iglesia y del matrimonio" (Rodríguez-Arenas, 1991, p. 87).

Finalmente y a propósito de la pareja de escritores, como pareja y como escritores, la edición completa del Diario íntimo de Soledad Acosta y del Diario íntimo de José María Samper (2015) que entrega Carolina Alzate resulta una lectura ineludible para los propósitos de este trabajo, pues si bien la relación amorosa entre ambos no es el objeto de este trabajo y los diarios pertenecen a una época relativamente temprana de estos autores -en cualquier caso anterior a la aparición de las obras objeto de estudio aquí-, se estima que la sensibilidad romántica proyectada en las reflexiones sobre la literatura y su lugar en el proceso fundacional, expresadas en sendos diarios, proporciona algunas claves para plantear un principio de interpretación e hipótesis de lectura frente a Mercedes y Florencio Conde: la posibilidad del mutuo amor y la unión matrimonial entre el negro y la blanca, pone a prueba la capacidad de la sociedad para enfrentar los cambios que supone la fundación de la nación moderna; ello equivale también a concretar y hacer frente a una contradicción histórica que tiene que ver con la desconcertante pervivencia de los valores derivados de una estratificación sociorracial colonial y la resistencia de la vieja sociedad a las ideas revolucionarias -vieja sociedad que se hace patente en algunos personajes de ambos relatos- que insiste en oponerse a que una mujer blanca, a más de bella y de noble origen, quiera o deba aceptar las pretensiones amorosas de un hombre negro. 


\section{La venganza de un ser falaz: encuentros y desencuentros entre la mujer blanca y el hombre negro}

Mercedes35 es un breve relato que narra la vida de Mercedes, una mujer de la clase mantuana bogotana, que a lo largo de la primera mitad del siglo XIX experimenta los cambios sociales derivados del proceso de la Independencia. A fin de enfatizar en la veracidad de la historia, la voz narrativa reproduce el modo en que la misma Mercedes, poco antes de morir, habría revelado los hechos de su vida a otra mujer, quien al inicio del relato funge como el personaje consignatario de lo narrado: "En largas conversaciones que tuvimos y ayudada por algunos datos que me suministró por escrito, creo haber reunido los principales rasgos de su vida, cuya narración he puesto en boca de ella, procurando imitar su lenguaje en cuanto me sea posible" (Acosta de Samper, 2006, p. 275)46. En Mercedes se configura el caso de un narrador intradiegético que crea, a su vez, otra historia interna y la provee de un segundo protagonista: ficción dentro de la ficción o bien la inserción de un mundo imaginario dentro de otro. En el plano temporal, la secuencia de lo narrado comprende los acontecimientos de la vida de Mercedes, desde su adolescencia hasta una edad cercana a los cuarenta años.

Los rasgos que describen al personaje central en su temprana juventud se corresponden con los de aquel tipo de mujeres descendientes de familias ricas españolas que durante el período colonial gozaron de las comodidades y el solaz propios de su clase, además de la posibilidad de educarse conforme a lo establecido para su sexo y posición social. El énfasis que se hace en el relato con respecto al origen del personaje, esto es, el explicitar que se trata de la "hija de un español" es, en opinión de Paulina Encinales, una señal del hasta entonces sujeto periférico de la mujer, presa de la cultura patriarcal dominante, rasgo común en muchas obras narrativas de Soledad Acosta y que busca afianzar "una voz y una autoría que se derivan del reconocimiento que se le confiere a su posición burguesa y aristocrática", lo que se constituye, además, en una "condescendiente autorización para incursionar en el mundo de la literatura (Encinales,1997, p. 399).

El estallido de la guerra de independencia marcó el inicio de una sucesión de tragedias morales y materiales de las cuales Mercedes se hace responsable atribuyéndose a sí misma, por vía de su propia insensatez, la culpa de lo sucedido. La dimensión didáctico-moralizante del relato -propio de la novelística romántica- busca persuadir al lector de los riesgos de no conducirse según los preceptos de la moral cristiana, pero sobre todo busca manifestar desconfianza frente a la mujer, esto es, evidenciar en el personaje cierta minoría de edad e impericia, si cabe llamarla así, que limita su capacidad de conocer y dominar

El relato hace parte de El corazón de la mujer. Ensayos psicológicos, obra publicada originalmente en 1869.

4 El texto citado corresponde a la versión digitalizada de 2006 por la Biblioteca Virtual Universal, donde se transcribe la paginación de la obra original. 
una naturaleza acaso pueril e irreflexiva que la lleva a experimentar fracasos en todos los órdenes. En este sentido Mercedes es una expresión representativa del modelo ideológico al que entonces se enfrentaba la mujer; el cuadro de vida que se pinta allí es una especulación sobre cómo debía ser pensada y entendida la mujer blanca -también por el hombre- de acuerdo con ciertos estereotipos.

El haberse declarado a favor del rey durante la primera etapa de la guerra de Independencia le hubiera costado al padre de Mercedes la pena de muerte, de no ser por la oportuna ayuda de Antonio, joven de su misma clase y admirador de aquella, quien atendiendo sus súplicas, y gracias a su influencia entre los líderes patriotas evita que dicha sentencia se aplique al viejo español. En 1816 Bogotá es retomada por los realistas y con ello se desatan el terror de los cadalsos y las persecuciones contra quienes habían participado de la primera Independencia, entre ellos Antonio quien, en una tentativa por ocultarse en la casa de Mercedes, cae preso en manos de los realistas. Al final del relato Mercedes se re-encuentra con Antonio y solo hasta entonces se entera de que este le había salvado la vida a su padre. Durante el triunfo transitorio de la reconquista la familia de Mercedes recupera su estatus y privilegios de clase. La cercanía del padre con la oficialidad del ejército realista propicia que ella conozca a Pablo, "un joven español, de noble aspecto, y tan elegante como hermoso [...] el cual penetró en mi corazón-confiesa Mercedes- como en país conquistado" (Acosta de Samper, 2006, p. 280).

En plena correspondencia de sentimientos, Pablo propone a Mercedes que deje a sus padres y escape con él a España, prometiéndole, además, que una vez allí se casaría con ella. En opinión de Ordóñez, esta figura de la joven y hermosa mujer criolla que se enamora con pasión del extranjero -al que ve como a un "conquistador" - y que se deslumbra ante lo extranjero, pareciera ser recurrente en las así llamadas "novelas psicológicas" de Soledad Acosta, y ello se desprende del análisis que hace de Laura (1870), un relato que guarda gran similitud -casi un calco- con Mercedes, tanto en el perfil que describe al personaje femenino, como en la trama que se teje en torno a la aparición de un extranjero francés que también le propone un amor oculto a través de la fuga. Ello da pie para que Ordóñez ponga de relieve lo que pareciera ser en Soledad Acosta una visión crítica de la fascinación por "lo extranjero" y así lo evidencia la voz narrativa en Laura: "A pesar de que para muchos basta ser extranjero para poseer todas las cualidades [...]" (Ordóñez, 997, p. 389), y lo anterior contribuye a reforzar, argumenta a renglón seguido Ordóñez, la relación entre nación y mujer que subyace en esta línea de relatos en los que se representa a la joven nación en la forma de la mujer inexperta y apasionada, huérfana, que se deja seducir y explotar por una nación extranjera. 
De regreso en el relato, una contingencia derivada de las obligaciones militares de Pablo precipita la marcha de este hacia Cartagena y con ello también el plan secreto de huida para Mercedes, plan que se ejecutaría en ocasión de una cabalgata en las cercanías de la ciudad y a la que asistirían, además de la pareja, varios distinguidos oficiales españoles. Encontrándose detenida la comitiva frente al paso de un grupo de prisioneros patriotas, entre ellos Antonio, Mercedes ejecuta con su cuerpo un torpe gesto de burla hacia estos, lo que trae como consecuencia la violenta reacción del animal que montaba, que se dispara en estampida haciéndola perder el control. Tras una trepidante carrera en la que Pablo intenta sin éxito salvarla, la joven cae al suelo perdiendo la consciencia y sufriendo serias heridas que desfiguraron su rostro y borraron para siempre la belleza que la hacía atractiva para Pablo y sobre la cual descansaban su vanidad y orgullo de mujer.

Después de semanas de agonía, la joven descubre en el espejo las secuelas del accidente y el alto precio al que se atienen quienes por cuenta de la vanidad desvían su ruta del ya prefigurado camino de la obediencia: "[...] muchos días imploré sinceramente al cielo que me diera la muerte, ya que me había quitado la belleza. Mas la Providencia me tuvo compasión y no quiso que muriera, para que tuviese tiempo de arrepentirme de mis faltas y expiarlas con terribles sufrimientos" (Acosta de Samper, 2006, pp. 282-283). Con la "expiación de las faltas", se manifiesta nuevamente la dimensión didáctico-moralizante del relato y se renombra el peso de una educación religiosa, cuya eficacia radica en el sentimiento de la culpa y en el miedo al castigo, o bien en lo que Vahos (2002) denomina la "labor preventiva del látigo y el cilicio", simbolismos que acompañaban la vida espiritual de los santos y santas que llegaron a América junto con la conquista española, y que servían de ejemplo edificante para la mujer. En este sentido resulta también atendible la reflexión de Encinales (1997) en torno a lo que considera la misión moralizadora en este género de relatos, que está dirigida no solo a "salvar a la mujer", sino también a sembrar la idea de que es precisamente a la mujer a quien corresponde salvar la sociedad a través del cristianismo y del perdón.

Al ya referido acto de contrición en Mercedes, se suma la dolorosa pérdida de Pablo, aquel hombre lleno de atributos que colmaba sus pretensiones de clase y quien habría perecido en la guerra, luego de haberse alejado para siempre de Mercedes, incapaz de conciliar la anterior imagen de belleza con la contrastante fealdad. Ante la llegada del ejército patriota a Bogotá y el inminente triunfo de la revolución, el padre de Mercedes es condenado al destierro en la población de Ubaque; a partir de entonces la otrora rica y prestigiosa familia experimenta el peso de una existencia menesterosa, cada vez más cercana a la miseria material, a la enfermedad y al hambre, a más de haber sido condenados en su comarca a una especie de ostracismo, ello porque se sabía de su cercanía con los realistas. 
Durante la marcha que debía conducir a la familia hacia Ubaque, entra en escena un personaje que llama la atención de Mercedes: “[...] un mulato, natural de Jamaica, que se había unido a nosotros en el camino; era mayordomo de un extranjero que poseía una pequeña propiedad a orillas del rio Negro. El mulato Santiago quiso hacerse aceptar en nuestra compañía manifestándose muy complaciente y amable conmigo" [mi énfasis] (Acosta de Samper, 2006, p. 289). La llegada de este hombre a su vida le ayuda a rehacerse del letargo en que se encontraba sumida y despierta en ella cavilaciones como la que sigue:

[...] deseando ardientemente que alguien (poco me importa quién) me admirase para tener la satisfacción de creerme amada; en esos días, digo, volvió a Ubaque el mulato Santiago ya en una posición muy diferente. Su patrón había muerto dejándolo heredero del terreno y casa que poseía cerca de Ubaque. Naturalmente el antiguo liberto se fue a radicar con orgullo en su propiedad y nos visitó, manifestando interés por nuestra salud. Lo recibimos con bondad, pues nos traía el eco de lo que pasaba en el mundo. A poco sus visitas se hicieron más frecuentes y nos llevaba siempre algún regalito de Bogotá, como buen pan, legumbres y frutas o dulces. Comprendí que sus visitas no eran desinteresadas, y fue tal mi ridícula vanidad, que no sentí disgusto con la idea de que aquel hombre pusiese sus ojos en mí, con pretensiones que en otros tiempos hubiera mirado con horror y rechazado como un insulto [mi énfasis] (p. 290).

El "poco importa quién" de cara a una perspectiva amorosa indica la aceptación, por defecto, de las pretensiones de Santiago: ante la irremediable ausencia de un pretendiente deseable, esto es, blanco, no queda otra alternativa que la aceptación de un negro, aún más cuando el anhelo afectivo coincide con una necesidad material concreta. De igual manera, para Santiago poco importaba el quién, porque aun pobre y deforme, se trataba siempre de una mujer blanca y de abolengo. Una vez abiertas las puertas de la humilde casa de Mercedes y ganada la confianza de la familia Santiago pide la mano de la joven a su padre, quien ante la audaz solicitud responde: "iQué inaudita insolencia! iUn mulato!, un antiguo esclavo, un miserable..., pedir la mano de mi hija" (p. 290).

Esta negativa afligió nuevamente a Mercedes, así como a la madre y a su hermana menor, que desde entonces echaron de menos no solo al admirador sino también sus generosas dádivas. Tal era la pobreza. Sin embargo, Santiago no ceja en sus intenciones de conquistar a Mercedes y la corteja furtivamente, manifestándole su cariño e insinuándole las ventajas que tendría para ella y su familia aceptar la oferta de matrimonio: "Me aseguraba -dice Mercedes- que solo deseaba ser mi humilde esclavo y que yo sería la señora y soberana de su hacienda y persona" (p. 291). En tanto las condiciones económicas empeoraron y el padre de Mercedes enfermó y murió. Mercedes se ve obligada a trabajar para sostener a la familia, pero lo que gana en poco o en nada cambia su situación de miseria. Las circunstancias animan nuevamente a Santiago a proponer matrimonio a Mercedes, quien aun sin el consentimiento de la madre conviene 
en contraer matrimonio secretamente con aquel: "Cuando volví esa tarde a casa era la esposa de un mulato, pero llevaba toda clase de víveres y vestidos para mi madre y hermana, que dije haber comprado con el producto de mis costuras" [mi énfasis] (p. 291).

No sobra citar aquí que este simbolismo del matrimonio en secreto también es utilizado de forma muy similar por Acosta de Samper en Laura (Ordóñez, 1997, p. 390), si bien en este caso lo que se esperaba procurase algo de confort a la pobre familia, y acaso también la esperanza del amor para Mercedes, se convierte en una pesadilla más, al persuadirse esta del propósito que perseguía Santiago casándose con ella: "[...] deseaba tener la satisfacción de que se supiese que una señora de las mejores familias de Bogotá era su esposa, y poderse vengar así de la sociedad que tantas veces lo había despreciado [mi énfasis]" (Acosta de Samper, 2006, pp. 294-295).

El matrimonio con una mujer blanca resulta, en la visión del negro, una especie de rito de paso, un medio para su aquiescencia como blanco, esto es, que si una mujer blanca ama a un hombre negro le está otorgando de alguna manera un estatus de blanco. De los estertores de esta visión arraigada en la idiosincrasia colonialista se hacen eco las reflexiones de Fanon en el ya citado ensayo, cuando evoca con indignación la artificiosa sensación de triunfo que experimenta el negro cuando se casa con una blanca: "Desposo la cultura blanca, la belleza blanca, la blancura blanca [...] En esos pechos blancos, que mis manos ubicuas acarician, hago mías la civilización y la dignidad blanca" (Fanon, 2009, p. 79). Esta faceta de la narración en Mercedes confirma, en últimas, que el negro se subordina a la división jerárquica que le ha impuesto el hombre blanco. Por otra parte, la maquinación de una venganza en el cuerpo y en la persona de la mujer blanca evidencia una treta de alguien que, presa de un conflicto inconsciente y sintiéndose íntimamente incapaz de superar el sentimiento de inferioridad, recurre a la construcción de una imagen artificiosa de sí, una "máscara", como alude Fanon, que le permita engañar a la contraparte blanca.

Un ejemplo bastante similar al del perfil moral que se dibuja del mulato Santiago en Mercedes es documentado por Barrenechea (2009) cuando aborda el análisis de una novela histórica chilena: El mulato Riquelme, obra en la que se construye un personaje que logra ascender socialmente gracias al ocultamiento del propio ser, ello como parte de una estrategia narrativa que se propone la demonización y la infantilización del rostro del negro. En esa misma dirección, Leonardo (2015) aborda en el análisis del ya citado relato La emplazada, de Ricardo Palma, la "imposibilidad" de la unión entre blancos y negros, no porque no puedan amarse, sino porque estos últimos, debido a su "principio africano", están condenados a volver a la barbarie propia de su origen, y ello les impide ser leales y constantes y los empujará tarde o temprano a "traicionar al blanco". 
En breve muere también la madre de Mercedes y el verdadero carácter de Santiago se manifiesta tal como es: "Con mucha frecuencia reunía en la casa a sus amigos, reuniones que se convertían siempre en estrepitosas orgías [...] Muy rara vez Santiago estaba en su juicio" (Acosta de Samper, 2006, p. 295). Con el fin de evitarle tal género de vida a su hermana, Mercedes consigue que esta sea aceptaba como costurera en la casa de una respetable señora de Bogotá, al tiempo que su vida transcurre en medio del desprecio por aquel mulato cuya violencia teme y de quien tiene también un hijo. En ocasión de uno de los convites de juego y bebida que se auspiciaban en su casa, Mercedes se rehúsa indignada a servirle la cena a Santiago y a sus amigos, provocando la ira de aquel:

\begin{abstract}
[...] al oír esto, me agarró del pelo y a empellones me obligó a entrar en el comedor. "iMercedes de Vargas! -exclamó-; tú, como hija de caballero tienes que servirnos humildemente..., a mí y a mis amigos. Para algo ha de haber servido la guerra de Independencia..." Cayéndome de vergüenza y horror, y bajo la mirada insolente de mando de aquel a quien había jurado, ante Dios, amar, obedecí sirviendo yo misma la cena. "Así me gusta -dijo él al cabo-; las blancas son cobardes siempre, y cuando uno las trata duro son una seda" Y acercándose quiso cogerme la mano con ademán cariñoso. Esto colmó la medida: no quise que me tocara, y situándome detrás de una silla le dije con la cabeza erguida y la mirada orgullosa: "He sufrido los insultos que usted me ha hecho, los que viniendo de un ser tan vil no vejan; pero no permito que se me acerque". Santiago, profiriendo horribles juramentos, tomó una botella para tirármela, pero sus compañeros se los impidieron (p. 296).
\end{abstract}

Uno de los asistentes a este sórdido episodio es Joaquín, viejo conocido suyo y compañero de luchas de Antonio, ahora entregado él también a los mismos vicios de Santiago. Reconociendo oportunamente en aquella desgraciada mujer a Mercedes, Joaquín se apresura a ayudarla a escapar y una vez al seguro le revela su identidad y le inquiere: "Pero usted a quien conocí rica, orgullosa y bella... ¿cómo la encuentro casada con este mulato despreciable?" (p. 297). Mercedes refiere con vergüenza los hechos de su vida a Joaquín, quien se conmueve y gracias a sus influencias consigue que ella y su pequeño hijo sean aceptados, con nombres cambiados, en una casa de familia respetable en Bogotá, donde haría las veces de sirvienta. En aquel lugar lograría Mercedes ocultarse de Santiago y llevar una vida pobre, pero tranquila. Al cabo de muchos años y gracias a la independencia económica que le proporcionan sus ahorros y el trabajo del hijo, deja su refugio para establecerse definitivamente en una casa propia, donde esperaba poder reconstruir su vida y su dignidad. Pero el hado persigue a Mercedes hasta el final de su corta vida, cuando reaparece Santiago, después de haber desperdiciado su fortuna en el vicio y ahora fugitivo de la ley. Haciendo uso de la intimidación y la violencia, el decadente Santiago perturba la plácida vida de la que fugazmente gozaron madre e hijo y se permite incluso extorsionarlos. La última de las tragedias que precede el final del relato viene 
con la pérdida del amado hijo, quien había sido reclutado en la revolución de 1840, de donde regresa fatalmente herido a morir en los brazos de Mercedes.

En Mercedes la ficción re-elabora la visión de una clase social estertórea, contraria a la revolución y tercamente aferrada al arquetipo racial de la colonia. En este sentido, la trama argumental induce al lector a concluir que, a más de lo atribuible a la vanidad y a la desobediencia en el personaje mujer, el trágico final de este amor demuestra que concederle la igualdad y la confianza a Santiago habría sido un esfuerzo estéril, dada la brutalidad y los impulsos primarios de aquel mulato incapaz de conducirse según los valores de los blancos, de la familia, de la ley.

En suma, se trata de la imagen desconcertante de un hombre que no estuvo a altura de aquel mundo que lo había acogido por vía de la legítima unión matrimonial, por una parte, pero, por otra, el relato evidencia algo más respecto a la faceta del amor al que a menudo aluden las novelas de Acosta de Samper y para ello se requiere evocar nuevamente el ejercicio de interpretación que hace Ordóñez en Laura, cuyo desenlace también termina con la muerte de la protagonista, muerte que es en cierto sentido una "muerte erótica", una desilusión, que se da paradójicamente después de haber roto con el esquema o la creencia de que "la mujer solo ama una vez y la traición no puede perdonarse ni el amor renacer" (Ordóñez, 1997, p. 393). Efectivamente, Mercedes amó al mulato Santiago después de haberse resignado a la pérdida del primer gran amor, blanco y español. Así se configura el simbolismo de la nación representada en la mujer y del cambio del paradigma colonial eurocéntrico (la muerte de Pablo es el fin de la Colonia) en favor de la aceptación de una comunidad nacional en la que, aun enfrentando resistencias, se insertan las poblaciones no blancas a los espacios sociales de la nueva nación.

\section{El amor interracial como expresión de un humanismo liberal}

El modelo de relación entre mujer blanca y hombre negro que se ensaya en Florencio Conde entrega, por su parte, una visión más optimista de cara a esta suerte de enlace. Las respectivas historias de amor, la del padre y la del hijo, fluyen ágilmente a la sombra de un discurso idealizado de la fundación de la nación que integra felizmente al negro al ámbito de la intimidad con la mujer blanca, al sobrio goce del erotismo, pero sobre todo a la posibilidad de ascender en la escala social, en virtud de una bien ganada fortuna, de una probada estatura moral y gracias también a que hay una República liberal y democrática que alienta el emprendimiento, la libre competencia económica y reconoce a todos los ciudadanos como iguales; en este sentido la voz narrativa, siempre en tercera persona, se desenvuelve como una reflexiva persuasión en favor del devenir 
histórico, una invitación a la aceptación de los cambios sociales y políticos que llegaban con los nuevos tiempos.

El escenario que enmarca el inicio de la narración en Florencio Conde es la aurífera provincia de Antioquia y el desarrollo de la historia cubre un período de tiempo que va desde finales del siglo XVIII hasta mediados del XIX. Si bien el título de la obra alude solo a uno de sus personajes, Florencio Conde, la vida de este es de alguna manera la prolongación del personaje que le precede en la historia, Segundo Conde, su padre, esclavo negro que habiendo nacido aún en la colonia y bajo el régimen socioeconómico de la hacienda, es destinado desde los dieciséis años al laboreo en las minas de oro.

En virtud de una ley colonial del Nuevo Reino de Granada, un esclavo tenía derecho a un día libre a la semana, el cual podía dedicar a trabajar por su propia cuenta incluso en la misma mina del amo. Si aquel llegara a ganar con su trabajo la cantidad necesaria para pagar su valor podía entonces comprar su propio "rescate" y ser así un hombre libre. Barrenechea (2009) documenta casos análogos en la literatura colonial chilena en los que el esclavo podía obtener la libertad por medio del propio trabajo o través de la manumisión. Con base en esta circunstancia y en una artificiosa teoría liberal de las ciencias naturales y del derecho universal, el narrador se propone dibujar una semblanza del hombre negro, que en virtud de poseer al igual que el blanco fuerza física y moral, puede redimirse a sí mismo por medio del trabajo, acumular riqueza y propiedad para llegar a ser un "hombre completo". La siguiente es la reflexión del joven esclavo en su primer día de trabajo por cuenta propia:

Hoy mi trabajo es mío, y el fruto de mi trabajo me pertenecerá. ¿Es decir que hoy soy hombre, no una cosa; soy un ente libre, no una bestia como los demás días de la semana? Sin duda ha de ser así, puesto que si el amo es una gran persona, un hombre rico, es por ser dueño de su hacienda, de su mina y de sus esclavos. Yo soy negro, negro como el carbón, y mi amo es blanco; pero tenemos mucha semejanza, a pesar de la diferencia de color y posición, puesto que él, que es mi amo, habla, come, siente, piensa y vive poco más o menos lo mismo que yo que soy su esclavo. ¿En qué consiste pues la mayor diferencia? En que él es un hombre, porque es libre y posee, y yo una cosa, una especie en bruto, porque soy poseído. ¿Pero no podré convertirme de cosa en hombre, a fuerza de trabajar todos los sábados y guardar lo que gane con este trabajo? ¿No lograré rescatarme con el oro de esta misma mina? Sin duda: así me lo ha dicho mi amo. Es preciso, pues, que yo tenga tanto como lo que pueda valer, para ser, sí, para ser algo (Samper, 1875, p. 17).57

La voz narrativa invoca la esencial homogeneidad biológica de la condición humana, esto es, que negro o blanco se habla, come, siente, piensa y vive igual en una u otra raza, y que en virtud de ello están llamadas a interactuar como

La ortografía y el uso de algunos signos de puntuación en las citas de Florencio Conde. Escenas de la vida colombiana se han actualizado con respecto a la primera y única edición de 1875. 
congéneres, aunque el amor sea solo mediado por el deseo del blanco, bien a través del amo - ama- mismo o, como lo será después, de la mujer blanca. Y es, asimismo, como se dan los primeros pasos en la construcción de un ente económico y productivo que nuevamente evoca la fundación de la nación en la imagen del joven negro, en este caso en lo que atañe a la producción de riqueza y el trabajo.

Efectivamente Segundo lograría con su ingenio y perseverancia no solamente pagar el propio rescate, sino también el de la madre y dos hermanas, también esclavas; ya con su trabajo libre en las minas lograría acumular en pocos años un capital apreciable que le permitiría vivir con la misma dignidad de un blanco. Esta integración del negro a la noción de la economía y del progreso que se ejecuta en la novela encuentra correspondencia con el escenario histórico posIndependencia en el que algunos privilegios de la clase dominante española y criolla serían suprimidos en beneficio de una clase emergente de mestizos y esclavos libertos, que gracias al talento y a la libre competencia pudieron acumular recursos que los harían visibles y los empoderaban con respecto a los blancos, en lo que un estudio de Germán Colmenares (1986) postula como "La decadencia de un sistema esclavista".

Pocos años después de consolidada la independencia, Segundo se desplaza hacia la provincia de Mariquita con su madre para establecerse allí y continuar sus actividades económicas, esta vez, con el comercio de animales y productos de la tierra. Un curandero que cuida infructuosamente de la quebrantada salud de la anciana madre de Segundo -que a la postre muere-enseña a aquel a leer, escribir y las operaciones básicas de aritmética. El adquirir estas habilidades ayuda a Segundo a entender que, a través de la educación podía llegar aún más lejos de lo que le permitía aquel relativo éxito económico, y que podía, aun con su conciencia afectada por el complejo de ser negro, dar pasos adicionales hacia la construcción de una personalidad individual, subir un peldaño más en la escala social. Al igual que en otras novelas de Samper, la figura del educador y de la educación que transforma a la sociedad es reiterativa (Cristina, 1976; Toro, 2010; Jaramillo Uribe, 1974).

En 1816, en medio del terror desatado por la reconquista española que perseguía a los patriotas de la primera independencia68 -proceso que Segundo desconocía gracias a que el amo se esforzó en ocultarlo- el joven esclavo había ayudado a ocultarse oportunamente y a escapar a un fugitivo blanco, un capitán del ejército de Bolívar que huyendo de los realistas intentaba llegar al sur de la Nueva Granada para reunirse con su esposa e hija. Este episodio recobra importancia para el relato cuando Segundo, tras la muerte de la madre, se establece en

$6 \quad$ Nótese la similitud con Mercedes en la elección de un escenario histórico para la narración. 
la población de Honda en 1822; allí asiste por casualidad al viático administrado a un moribundo, un tal coronel Samudio, hombre que, aunque pobre, gozaba de gran prestigio entre los pobladores gracias a su heroica participación en la guerra de Independencia. Aquel hombre, ya en su lecho de muerte y acompañado de su hermosa hija reconoce con emoción al esclavo que le había salvado la vida años atrás y al que debía profunda gratitud. Antes de morir, el coronel Samudio refiere con dificultad a Segundo parte de su lucha junto al Libertador y los sufrimientos que había padecido por causa de la enfermedad y la pobreza; finalmente, en acto bizarro, encomienda a Segundo su espada y la suerte de su hija, quien ya tenía conocimiento de la existencia del esclavo y de lo que este había hecho por su padre. El cuadro que encierra la muerte del coronel Samudio constituye el preludio al romance entre Segundo y la hija de aquel:

Camila mía, ya me voy... esto acaba; óyeme. ¿Serás tú capaz de acatar mi última voluntad, cualquiera que fuese? -Sí, padre mío, respondió ella con seguridad; haré todo lo que usted me mande-. -Y tú, Segundo, ¿aceptarías cualquiera manda que yo te hiciese o dejase?- iCualquiera mi capitán! -Pues te dejo mi hija, mi único bien, y te la dejo en completo desamparo, sola en el mundo [...] Si ella no tuviese repugnancia por ser tú negro, cásate con mi hija y hazla feliz. Si esto no pudiese ser, protégela con caridad y bondad como tu hija o tu pupila [...] Camila con los ojos humedecidos se acercó a Segundo y le estrechó las manos, con lo que por un memento se entrelazaron el marfil y el ébano en un cordial apretón que expresaba los más delicados sentimientos [mi énfasis] (Samper, 1875, pp. 83-85).

La admirable actitud del héroe de la independencia que invita al negro a formar familia con su hija, en una evocación a la igualdad en el proyecto de nación, se desdibuja con el "si ella no tuviese repugnancia", pues denota la remanencia de la fealdad y de la inferioridad en la prefigurada imagen del negro. Siendo ya un hombre de recursos, Segundo aporta con generosidad los medios necesarios para el sostenimiento económico de la huérfana en la casa de personas respetables; sin embargo, por ser "naturalmente delicado" (p. 87), no osa en principio tomar la voluntad del padre de esta en un sentido literal, sino más bien asume la responsabilidad de protegerla sin esperar a cambio más que el cariño de Camila, a quien trata con sumo recato y humildad, guardando siempre una respetuosa distancia. Sería por el contrario ella, Camila, quien trae a la memoria lo dicho por el padre como su último deseo, esto es, que Segundo fuera su esposo y no solo su protector, a más de manifestar que ella estimaba a los hombres por sus calidades y virtudes y no por su color.

Con lo anterior, la hija supera al padre, manifestando implícitamente no sentir repugnancia por aquel hombre y habiendo superado para siempre uno de los prejuicios raciales que le impedían a esa sociedad alcanzar la plena independencia. Camila tiene un brillo especial entre los personajes mujeres de la novela: representa sin duda el carácter moderno y progresista que exalta 
el narrador en algunos sujetos históricos que articula a lo largo del relato. Su percepción renovada del hombre negro y la iniciativa que ella misma elige tomar frente a él, bien por amor o por gratitud, ponen en marcha y llevan a la práctica el proyecto de nación en la conformación de una familia interracial. El siguiente diálogo consolida la futura unión entre la pareja y otorga a Segundo la providencial recompensa, impensable en el horizonte de esperanzas de alguien que nació esclavo: una mujer blanca, hija a su vez de un noble caballero héroe de la independencia:

Sí; él quiso que yo fuera la esposa de usted. -iOh! iNo hable usted de eso, mi señorita!- repuso Segundo; yo soy un liberto, un negro, y no he pensado sino en llenar los grandes deberes de... Protector de la hija del patriota coronel... -Y usted Segundo, interrumpió Camila ¿no querría ser algo más que mi protector?- [...] Camila se puso en pie con noble continente, y acercándose a Segundo y mirándole con una expresión de sublime candor le dijo: -Responda usted: ¿querría usted casarse conmigo? Segundo cayó maquinalmente a los pies de Camila, de hinojos y con las manos puestas en actitud de súplica y agradecimiento infinito. -Pues hágase la voluntad de Dios y de mi padre, añadió Camila, tendiendo la mano a Segundo-. ¿Y la de usted? dijo este con timidez. La mía también, Segundo [...] Segundo la estrechó en los brazos, y el blanco cuello de paloma de Camila reposó durante un largo minuto sobre los negros y lanudos cabellos del dichosos liberto [mi énfasis] (pp. 95-96).

El lenguaje del cuerpo adquiere un alto poder de representación en el anterior pasaje, y con ello el narrador advierte una tensión social y política aún latente, la presencia de una fuerza reaccionaria que pone en riesgo la emancipación, y que tiene que ver con la idealización estética de la raza blanca y la imagen blanca de Dios, producto de la colonización religiosa; en efecto, era ante sus amos, un juez, Dios, la Virgen o los santos que se arrodillaba un negro en aquella época, lo que significaba estar en la presencia de lo divino, lo bello, lo sublime, lo todo poderoso. Camila es para Segundo el híbrido de todo ello. Ante la presencia de estas expresiones de mestizaje y transculturación ficcionalizadas en las obras en cuestión -obras que constituyen en sí pasos en la creación de una tradición literaria y una historia cultural en la joven nación- resulta atendible el punto de vista de Ortiz Tirado (1983), para quien las uniones interculturales no obedecen siempre a patrones fijos ni generan siempre los mismos resultados: cada cultura puede trascender algunos de sus componentes originarios, al tiempo que asimila los de otra cultura y con ellos crea nuevos parámetros culturales y transposiciones estéticas, que involucran tanto a negros como a blancos en una nueva semiótica del cuerpo, en nuevo lenguaje, en una re-significación de los símbolos, que serán el producto emergente, la síntesis y sumatoria de la cual Camila y Segundo son un ejemplo edificante.

Con la consumación de este unilateral matrimonio -pues es solo ella quien lo determina porque solo ella podía admitirlo- se concluye la primera parte del relato, y la segunda se inicia tras un salto en el tiempo de más de veinte 
años, con la descripción de un episodio que confirma el "éxito" social, moral y económico de la referida unión: la vida como estudiante de Florencio Conde, hijo de Segundo y Camila, en la Universidad de Bogotá: “Tenía aquel joven en las facciones y en todo el continente los rasgos patentes de un feliz cruzamiento de razas, de suerte que, siendo un verdadero mulato, era lo que puede llamarse un hermoso mestizo [...] Era alto, delgado, de formas elegantes y de movimientos desembarazados; tenía la tez casi blanca, pero de un blanco mate [...]" (Samper 1875, p. 101); aquel joven junto con su hermana se habían trasladado a la capital para estudiar y poderse relacionar con gentes de prestigio, eran los beneficiarios de la fortuna que había acumulado ágil y pacientemente el liberto Segundo con su trabajo en las minas de oro y en el comercio.

Siempre consciente de la condición aun no blanca de sus hijos, Segundo cavila cómo hallar medios o caminos que condujeran a aquellos hacia el reconocimiento social, y con ello hacer abstracción de su complejo de raza: "haga yo feliz a mi hijo, dándole buena educación y procurándole riqueza con mi trabajo y economía, poco importa que yo me prive de su compañía, si él alcanza la posición en que deseo verle" (106), esto respecto a Florencio, mientras que con relación a Antonia, la hija menor "decía para su sayo y con malicia: mi Antoñita será con el tiempo una señorita bien educada, y la educación, a más de la fortuna, le borrará para muchos el defecto de ser mulata" [mi énfasis] (p. 108).

Nuevamente el fantasma de la vieja sociedad reaparece en los complejos de Segundo que evocan las repulsivas maquinaciones de Santiago, el antihéroe negro en Mercedes; pero más allá de eso, la referencia a la tez "casi blanca" de Florencio está aludiendo a otra creencia de origen colonial fuertemente arraigada: el blanqueo de las razas, esto es, que a más entrecruzamiento de mestizos con blancos más se esclarecía el color de la piel y más lejano se estaba del "defecto" racial, defecto que Segundo advierte como evidente en su hija. En este sentido Florencio Conde dialoga con Sab, de Gertrudis Gómez de Avellaneda, en donde también se aborda el tema del blanqueamiento en relación con las expectativas de la cultura blanca.

No obstante su muy cómoda posición económica, su título universitario y el creciente prestigio como orador y publicista en la naciente República liberal de la década de los cuarenta, Florencio era víctima de desprecios y discriminaciones en el medio aristocrático en que pretendía insertarse. En ese contexto y ya dotado de un ego que contrasta con la natural humildad de Segundo, esto es, reforzado por el ejemplo de superación del padre y el nada despreciable abolengo que le otorgaba ser nieto de un blanco de origen español, a más prócer de la Independencia, el joven abogado se enamora con pasión de la bella y elegante Rosita Fuenmayor, descendiente de una familia de nobles españoles: "lozana, 
blanca como el jazmín, y de cabellos de un rubio castaño y ojos de un azul garzo y brillante" (p. 113). La familia de Rosita y ella misma se describen en la narración como seres altivos y racistas; si bien su prestigio y fortuna menguaban cada vez más por cuenta del cambio social operado por la Independencia, aquellos permanecían apegados a los valores e ideas de la Colonia y sobre todo al esclavismo, en suma, nada menos favorable a las intenciones de Florencio. En ocasión de un baile de etiqueta al que es invitado por un amigo ministro y en el cual se encuentra presente Rosita, Florencio aprovecha la oportunidad para invitarla a bailar la contradanza, petición que es de inmediato rechazada con desdén por la joven, quien al ser interpelada más tarde por una de sus amigas respecto del motivo de su conducta responde: "iPuf! Yo nunca bailo con mulatos [...] mi padre me ha dicho que ningún hombre de color puede ser caballero (p. 127)". Florencio, quien había permanecido cerca de Rosita sin que esta lo advirtiera, alcanzó a escuchar el breve diálogo entre las amigas y tal señal de desprecio le causó, a más de una gran tristeza, un desmayo que no pasó desapercibido a la atención de aquella, quien comprendería desde entonces que aquel joven mulato la amaba.

Tras lo ocurrido Florencio decide renunciar al amor de Rosita y dedicarse a su carrera de jurisprudencia. En esta instancia del relato y en la persona de Florencio se evidencia una significativa tensión derivada del proceso de mestizaje en una etapa más avanzada, si cabe llamarlo así, en la cual un individuo producto de la exitosa síntesis biológica de dos razas diferentes, una dominante y otra subordinada, es admitido -no sin encontrar resistencia- en los círculos y actividades sociales de la clase dominante, ello en virtud de su cuasi blancura fisionómica y de las influencias que se derivan de su riqueza y prestigio intelectual.

En el sentido de cómo se insertan los productos emergentes del mestizaje en los sistemas políticos y económicos tras la independencia, y de la realidad excluyente que se oculta tras el concepto de "inclusión" del otro, Magnus Mörner (1969) y Peter Wade (2003) aportan algunos elementos que explicarían en parte la presencia de las resistencias al cambio de percepción del mestizo que son objeto de ficcionalización en los relatos en cuestión: si bien con la Independencia se suprime la división de índole sociorracial que imperó en la Colonia, el color de la piel sigue estando en el centro del estatus y la reputación social de los individuos, así como en la conducta que se asume ante ellos; solo en la medida en que los niveles económicos y culturales de los mestizos lograban igualar o aproximarse al de las clases dominantes, fueron más frecuentes las uniones interraciales. A la luz de este argumento, adquieren sentido no solo la aceptación de Florencio en un baile de etiqueta, al cual es invitado nada menos que por un amigo ministro, sino también la posibilidad de que, soslayando su origen racial, Rosita dé por admisible sus pretensiones amorosas, como ocurriría ulteriormente. 
En cierta ocasión mientras asistía a una diligencia en un juzgado, Florencio se entera de que don Pedro Fuenmayor, el padre de Rosita, está por ser embargado en todos sus bienes, incluida su casa de habitación, por cuenta de deudas no pagadas. Sin dar aviso al deudor y con una calculada bondad, el astuto joven se apresura a entrar en contacto con los acreedores de Fuenmayor y se hace procurar una ingente cantidad de dinero de su padre, a fin de pagar las obligaciones contraídas por el viejo mantuano quien, ya informado del embarazoso episodio del baile que involucraba a su hija, no tardaría en presentarse ante Florencio a inquirir el porqué de semejante conducta. Florencio manifiesta que su acto no persigue ningún interés distinto al de querer salvar a una respetable familia de la ruina y que no espera recibir nada cambio, a más de asegurar a don Pedro que, contrario a lo que este creía, no buscaba tomar venganza por lo acontecido con Rosita ni mucho menos afectar o disminuir el honor de su familia. Sintiéndose humillado y presa del desconcierto por la insólita actitud del joven mulato, el padre de Rosita insiste con desesperación en pagar a Florencio el dinero del rescate entregándole la colección de joyas y piedras preciosas de la familia, proposición a la que se resiste Florencio con disimulada indolencia, si bien finalmente convienen, por cuenta de la intransigencia del viejo, en que este firmaría un pagaré a nombre de Florencio y se comprometería en el pago de un interés mínimo, de manera tal que no se viera afectada la ya insolvente economía de la familia Fuenmayor.

Por varios años se mantuvo Florencio alejado de la familia Fuenmayor y en medio de esto decidió realizar un viaje por Europa, en donde entró en contacto con diversidad de culturas y expresiones políticas que alimentaron su criterio ideológico y lo llevaron a percibir, aunque de modo rudimentario, la noción de lo que ulteriormente el discurso socialista acuñaría como lucha de clases. En 1848 presenció los acontecimientos que sirvieron de marco a la Comuna de París, revolución que despertaría en él las siguientes reflexiones:

Recordó entonces que su patria era una república compuesta de muy diversas razas, combinadas sobre un suelo virgen y rico para fundar sobre su propia mezcla el imperio de la democracia liberal; pero que ni en la patria neo-granadina existía el gobierno del pueblo, ni la república había procurado suficientemente la emancipación de los oprimidos. "Aún hay esclavos en mi patria [...] ila raza de mi padre es tiranizada por la de mi madre! iNo! iEso no puede ser, no debe ser! Eso es un horrible contrasentido, y mi existencia misma no está en armonía con la vida política de la sociedad a que pertenezco !Eureka! Ya sé cuál es mi fin, cuál debe ser mi idea fija y el objeto de todos mis desvelos. Dedicaré todo lo que soy y lo que pueda ser al cumplimiento de este propósito: hacer primero que desaparezca totalmente la esclavitud y procurar luego que el cruzamiento material de nuestras razas se reproduzca en un grande hecho moral: la promiscuidad democrática del gobierno y la justicia cristiana de las leyes [mi énfasis) (Samper, 1875, pp. 158-159). 
En la cita anterior, que dicho sea de paso evoca el célebre juramento de Bolívar en el Monte Sacro, se pone nuevamente de manifiesto esa tendencia del siglo XIX por sacar a la luz formas narrativas en las que los discursos histórico y literario se aproximan y entrecruzan, haciendo que el destino individual de los héroes -o bien de los personajes- se funda de modo épico o dramático en el sentido global de lo histórico, pues aquellos son dotados de una suerte de voluntad constructiva en torno a la cual se organizan los acontecimientos en la narración. Germán Colmenares (1987, p. 169) atribuye esta tendencia de la historiografía y las literaturas finiseculares en Hispanoamérica a la influencia que entonces tuvieron las novelas históricas de sir Walter Scott y de su imitador Washington Irving.

Florencio regresa a la Nueva Granada el año siguiente e inspirado por la experiencia europea añade a sus actividades sociales una especie de militancia y se entrega a la causa de la abolición de la esclavitud; en esa dirección incursiona en el periodismo y se dedica al estudio de temas políticos, integrándose, además, a los círculos liberales que para mediados de siglo perseguían ideales progresistas, entre estos el que lideraba el general José Hilario López, figura histórica en cuyo gobierno es decretada la abolición definitiva de la esclavitud en la Nueva Granada en 1852, con lo que se evoca un rasgo autobiográfico de Samper (Jaramillo Uribe 1974; Toro 2010; D'Allemand 2012).

Esta irrupción de Florencio en la lucha política evoca nuevamente un rasgo sobresaliente en esta obra de Samper y acertadamente señalado por Toro (2010) en su análisis de Florencio Conde: la lucha generacional de sus personajes, padre e hijo, por alcanzar la libertad, lucha que, además, se libra en escenarios burgueses como se muestra a continuación. La amistad con Luis Fuminaya, un joven aristócrata a quien Florencio había salvado la vida con su oportuna intervención tras un duelo, lo lleva a reencontrarse después de tres años con Rosita Fuenmayor, a la sazón prima de aquel. Contrario a lo que Florencio hubiera esperado, la joven había estimado con gratitud la indulgente generosidad para con ella y su familia y se hallaba ahora en una actitud diferente hacia él: la repulsión que mostró en principio se había transformado en íntima admiración y simpatía por aquel talentoso hombre que progresivamente se ganaba el respeto de las elites políticas y la sociedad aristócrata de la capital. Frecuentar la casa de los Fuminaya permitió a Florencio cultivar también la amistad de Rosita, amistad que terminaría por convertirse en mutuo afecto y secreto enamoramiento. Ya enterado del recíproco amor entre los jóvenes y a fuerza de saldar de una vez por todas la deuda contraída con Florencio años atrás, Pedro Fuenmayor había hipotecado su casa de habitación y por cuenta de ello se encontraba nuevamente al borde de la ruina absoluta, a más de que comenzaba a dar señales de demencia y serio deterioro de la salud. Florencio rescata a la familia Fuenmayor de una ignominiosa indigencia a la que estaba 
destinada, pagando otra vez en secreto al acreedor de don Pedro el valor de la referida hipoteca. Esta circunstancia, que se presenta en el contexto de una serie de cambios derivados del establecimiento de la democracia liberal y de la noción de igualdad de todos los hombres ante la ley que se promulgaba en los círculos políticos e intelectuales, es aprovechada por Florencio para ganarse el favor de la madre de Rosita, doña Tadea, a quien se propone persuadir -dado que el padre no se encontraba en pleno uso de su facultades- de la conveniencia moral y económica de aceptar su propuesta de matrimonio con Rosita:

Todo mi defecto ante los ojos de usted y de don Pedro, consiste en que soy mestizo ¿pero importa esto, si soy un hombre de honor y muy capaz de hacer feliz a mi señorita Rosa? [...] Por otra parte, agregó Florencio, tengo una posición independiente y honrosa y soy relativamente rico: nada me sería más grato que poner cuanto tengo y soy al servicio de usted y su familia. Sí, es preciso que yo sea muy explícito y hable con franqueza. Don Pedro ha perdido ya todos sus bienes y fortuna; no tiene de qué vivir y su casa está hipotecada y perdida; y la triste situación en que se halla proviene de un trance muy penoso en que su dignidad ha sido cruelmente humillada por un acreedor implacable. ¿Qué esperanza puede haber para don Pedro y su familia? [mi énfasis] (Samper, 1875, p. 202).

Admitiendo que no existía otra salida a la crisis económica y sin dejar de reconocer la virtud en Florencio, la afligida señora aprueba a nombre suyo y de su esposo la unión entre los jóvenes. El matrimonio se celebraría en breve y como respuesta a la invitación que hace Florencio a Segundo, su anciano padre que se encontraba en Honda, este le responde en una carta: "[...] cásate pronto y no me aguardes. Mi presencia en tu casamiento sería una humillación para la familia de tu esposa y acaso para esta misma, y no quiero amargar lo que debe ser todo felicidad y contento. Puedes disponer de treinta mil pesos en oro que tengo reservados para ti [mi énfasis]" (p.204). Nótese como "lo negro", representado en el padre de Florencio, termina por ocultarse a los demás, para dejar visible solo la figura del hijo, ya "blanqueado".

En el último capítulo de la novela, "El regalo de boda", se describe la sencilla ceremonia matrimonial que tuvo lugar en la casa de Rosita y ante un juez civil, circunstancia esta última inusual para la época, pero que alude al alcance que se le quiere atribuir al naciente régimen republicano. En ella Florencio enseña ante el pequeño grupo de invitados el documento que libraba la hipoteca y restituía la propiedad de su casa a la familia Fuenmayor. Milagrosamente el padre de Rosita recupera la lucidez instantes antes de que concluyera la ceremonia; en esto la joven hace un último intento por obtener de él la bendición y acompaña su tentativa con la noticia de que Florencio había pagado la hipoteca de la casa y de que gracias a ello se encontraban ahora salvados de la ruina. A continuación el diálogo que cierra el relato: “-¿Dónde está Florencio Conde? Aquí, dijo Florencio acercándose al anciano con profundo respeto. ¿Me aceptaría usted por su hijo 
a pesar de...?- Un español noble, contestó el anciano tendiéndole las manos, puede sin desdoro aceptar por hijo al más noble de los hombres, siquiera sea un mestizo [...]" (p. 210).

Aparte de que también las estrategias de persuasión de Florencio para ganar a Rosita evocan el oscuro oportunismo de Santiago en Mercedes, persiste el sentimiento de inferioridad con que el narrador blanco inviste a Segundo; es la medida física y moral ineluctable que le corresponde al hombre negro, "la librea" que le ha hecho el hombre blanco y que el negro debe enfundarse, parafraseando nuevamente a Fanon (2009, p. 60), a cambio de ser considerado sujeto histórico, afectivo, económico. De igual manera el padre de Rosita, que en ocasión de su pragmática rendición ante el peso de la realidad y de la historia, no deja de manifestar una convicción racista. Segundo Conde y Pedro Fuenmayor son expresión de la vieja sociedad, pero una expresión perenne.

\section{Conclusión}

Las obras objeto de estudio en este trabajo constituyen un medio propicio para repensar desde una perspectiva socio-literaria la noción de un "amor racialmente promiscuo" y la construcción de una inter-subjetividad que desde allí se da, siendo, a su vez, ambos expresiones del tipo de relatos que documenta Doris Sommer como "una intimidad nacional" en los que el amor, la política y la historia se entretejen de manera ficcional y como parte de un proceso conflictivo de creación de una identidad nacional que va de la mano con una nueva literatura nacional. En este sentido y con base en la existencia de un corpus importante de obras y de autores en el ámbito del siglo XIX, parece evidente que el romanticismo colombiano y el latinoamericano se sintieron seducidos por la representación literaria de relaciones interraciales (mujer blanca-hombre negro; hombre blanco-mujer negra), no necesariamente amorosas, compartiendo así varias de las misma inquietudes éticas y estéticas. Con todo, en ambas obras viene representado el conflicto que presupone fundar una nación moderna con homogeneidad de derechos y se pone a prueba, en el amor interracial entre el negro y la blanca, la esencia de la nación misma. Finalmente sendas obras pueden ser también entendidas como parte de los escenarios sociales e imaginarios asociados al negro, al amor y a la familia que estuvieron en boga durante el periodo de transición entre la Colonia y la vida republicana, al tiempo que se presenta un cuadro del proceso fundacional de la nación que experimenta un conflicto entre el pensamiento tradicional y el moderno.

\section{Referencias bibliográficas}

Acosta de Samper, Soledad (2006). El corazón de la mujer. Ensayos psicológicos. Versión digital de la obra de 1869. Recuperada el 05/05/2015 del sitio: http://www.biblioteca.org.ar/libros/131014.pdf 
Alzate, Carolina (2015). Diario íntimo de Soledad Acosta \& Diario íntimo de José María Samper. Bogotá: Universidad de los Andes \& Instituto Caro y Cuervo.

Alzate, Carolina y Ordoñez, Montserrat (2005). Soledad Acosta de Samper. Escritora, género y nación en siglo XIX. Madrid-Frankfurt: Iberoamericana Editorial Verveurt.

Barrenechea, Paulina (2009). El rostro más negro. La travesía literaria de un bandido-cimarrón en Chile. Revista Chilena de Literatura, n. ${ }^{\circ}$ 74, pp. 197-211.

Colmenares, Germán (1968). Partidos políticos y clases sociales. Bogotá: Universidad de los Andes. (1986). La Independencia. Ensayos de historia social. Bogotá: Colcultura.

(1987). Las convenciones contra la cultura. Bogotá: Tercer Mundo Editores.

Cristina, María Teresa (1976). Novela y sociedad en José María Samper. Razón y Fábula, Revista de la Universidad de los Andes, n..$^{\circ}$ 42, pp. 5-47.

D’Allemand, Patricia (2012). José María Samper. Nación y cultura en el siglo XIX colombiano. Bern: Peter Lang.

Douglas, Frederick (2013). Vida de un esclavo americano contada por él mismo. Santander: Editorial Barrio.

Edgeworth, María (1986). Belinda. London: Pandora Press.

Encinales de Sanjinés, Paulina (1997). La obra de Soledad Acosta de Samper: ¿un proyecto cultural?. Memorias. IX Congreso de la Asociación de Colombianistas: Colombia en el contexto latinoamericano. Bogotá: Universidad de los Andes.

Fanon, Frantz (2009). Piel negra, máscaras blancas. Madrid: Akal.

Gómez de Avellaneda, Gertrudis (2003). Sab. Versión digital de la obra de 1841. Recuperada el 21/05/2015 del sitio: http://www.biblioteca.org.ar/libros/70100.pdf

Jaramillo Uribe, Jaime (1974). El pensamiento colombino en el siglo XIX. Bogotá: Temis.

Leonardo, Richard (2015). Los negros no saben amar. Nación, representación y exclusión en "La emplazada" de Ricardo Palma. Letras, 86 (123), pp. 141-158).

Mörner, Magnus (1969). La mezcla de razas en la historia de América Latina. Buenos Aires: Paidós.

Ordóñez, Montserrat (1997). Soledad Acosta de Samper: ¿un intento fallido de literatura nacional?. Memorias. IX Congreso de la Asociación de colombianistas: Colombia en el contexto latinoamericano. Bogotá: Universidad de los Andes.

Ortiz Tirado, Fernando (1983). Contrapunteo cubano de la caña y el azúcar. La Habana: Pensamiento cubano. Editorial de Ciencias Sociales.

Palma, Ricardo (1977). "La emplazada". Cien tradiciones peruanas. Selección de José Miguel Oviedo. Caracas: Biblioteca Ayacucho.

Rama, Ángel (1985). "Autonomía literaria americana". Crítica de la Cultura en América Latina. Caracas: Biblioteca Ayacucho.

Rodríguez-Arenas, Flor María (2004). El realismo de medio siglo en la literatura decimonónica colombiana: José María Samper y Soledad Acosta de Samper. Estudios de Literatura Colombiana, n. ${ }^{14}$, pp. 55-77. 
Rodríguez-Arenas, Flor María; Robledo, Ángela y Jaramillo, María (1991). Soledad Acosta de Samper, pionera de la profesionalización en la escritura femenina colombiana: Dolores, Teresa la limeña y El corazón de la mujer (1869). ¿Y las mujeres? Medellín: Universidad de Antioquia.

Samper Agudelo, José María (1875). Florencio Conde. Escenas de la vida colombiana. Bogotá: Imprenta de Echeverría.

Sommer, Doris (2004). Ficciones fundacionales. Las novelas nacionales de América Latina. Bogotá: FCE.

Toro Murillo, Alejandra (2010). Florencio Conde y los valores de la nación de acuerdo con la ideología liberal de José María Samper. Estudios de Literatura Colombiana, n. ${ }^{\circ}$ 27, pp. 97-118.

Vahos, Luis Arturo (2002). Mujer y educación en la Nueva Granada. Bogotá: Comunicación Creativa.

Villaverde, Cirilo (1981). Cecilia Valdés o la loma del Ángel. Caracas: Biblioteca Ayacucho.

Wade, Peter (2003). Repensando el mestizaje. Revista Colombiana de Antropología, n. ${ }^{\circ} 39$, pp. 273-296.

Williams, Raymond (1991). Novela y poder en Colombia. Bogotá: Tercer Mundo. 